\title{
Piece of Evidence. Commentary: Ancestral Mental Number Lines: What Is the Evidence?
}

\author{
Rosa Rugani ${ }^{1,2 *}$, Giorgio Vallortigara ${ }^{2}$, Konstantinos Priftis ${ }^{1}$ and Lucia Regolin ${ }^{1}$ \\ ${ }^{1}$ Department of General Psychology, University of Padova, Padova, Italy, ${ }^{2}$ Center for Mind/Brain Sciences, University of \\ Trento, Rovereto, Italy
}

Keywords: numerical cognition, number sense, domestic chick, spatial numerical associations, mental number line

\section{A commentary on}

Ancestral Mental Number Lines: What Is the Evidence?

by Núñez, R., and Fias, W. (2015). Cogn. Sci. doi: 10.1111/cogs.12296. [Epub ahead of print].

OPEN ACCESS

Edited by:

Jennifer Vonk,

Oakland University, USA

Reviewed by:

Alexis Garland

Ruhr University Bochum, Germany Michael Beran,

Georgia State University, USA

*Correspondence: Rosa Rugani rosa.rugani@unipd.it

Specialty section:

This article was submitted to Comparative Psychology, a section of the journal

Frontiers in Psychology

Received: 10 March 2016 Accepted: 04 April 2016

Published: 22 April 2016

Citation:

Rugani R, Vallortigara G, Priftis $K$ and

Regolin L (2016) Piece of Evidence.

Commentary: Ancestral Mental

Number Lines: What is the Evidence?

Front. Psychol. 7:553.

doi: 10.3389/fpsyg.2016.00553
In a recent comment, Núñez and Fias (2015) argued that our study (Rugani et al., 2015a) failed to demonstrate the existence of a linear numbers-space mapping. Defining the specific structure (straight vs. curve line, logarithmic vs. linear, $2 \mathrm{D}$ vs. 3D, hyperbolic or parabolic!) of chicks' (or newborn humans') number-space mapping was not the aim of our research (Rugani et al., 2015a). The aim of our study was, instead, to investigate the existence of spatial numerical associations in subjects without language or cultural experience (i.e., chicks), independently of the exact nature of this association. We found that 3 -day-old domestic chicks associate small numbers with the left side of space and large numbers with the right one (Rugani et al., 2015a), excluding a role of language or culture on the original number-space association. Therefore, we claimed that number space mapping in chicks resembles the humans' Mental Number Line (MNL), a well-known description of the fact that adult humans associate small numbers with the left side and large numbers with the right side (Umiltà et al., 2009; Dehaene, 2011).

Núñez and Fias's rebut our results because they do not comply with a mathematical definition of linear mapping. A focus about literal definitions, however does not detract interest from the fact that evidence has been recently accumulating of the existence of language-independent associations of space and number (Rugani et al., 2007, 2010, 2011, 2014; de Hevia and Spelke, 2009, 2010; Lourenco and Longo, 2010; Adachi, 2014; Drucker and Brannon, 2014; Bulf et al., 2016).

Besides being overly concerned with the appropriateness of definitions, Núñez and Fias claim that our results could be explained in terms of chicks' asymmetric behavior. Indeed, several behavioral asymmetries have been demonstrated in chicks (Daisley et al., 2009; Rogers et al., 2013); in all these cases biases referred to well defined responses scored for one side consistently exceeding those scored for the opposite direction. Nonetheless, this was not our case because, in contrast with Nunez and Fias claim about our analyses, we showed that our chicks' performance was symmetrically distributed around a mean of 0.50 (i.e., chance level suggesting lack of asymmetry), and it was equally distributed across all conditions (small vs. large number trials) and across all experiments. We would like to encourage whoever is concerned (as well as Núñez and Fias) to directly re-compute the analyses from our dataset available online (Rugani et al., 2015a,b).

Núñez and Fias also commented that, because in our experiments chicks experienced a number during training and new numbers during testing, the novelty effect could be produced by an asymmetrical processing that could explain chicks' behavior. That is, given the logarithmic 
compression of the human MNL (but never demonstrated in chicks), large numbers are more difficult to be distinguished from the reference (less novelty), whereas small numbers are easier to be distinguished from the reference (more novelty). First, it should be noticed that responses to "novelty," in the articles quoted by Núñez and Fias, were guided either by the left hemisphere (Vallortigara et al., 1996) or, by means of different paradigms, by the right hemisphere (Vallortigara and Andrew, 1991); thus, novelty processing cannot be systematically associated only with one hemisphere. Second, even if novelty were processed by the right hemisphere of our chicks, leading them to associate small numbers with the left side of space, there is no explanation why larger numbers would be associated with the right side of space, unless we hypothesize that in this case less novelty is processed by the left hemisphere! We suggest, instead, that the direction of bias that we found, even on the very first test and on the very first trial (Rugani et al., 2015b), was actually opposite depending on the initial training and as a function of number magnitude. For instance, when chicks were trained on

\section{REFERENCES}

Adachi, I. (2014). Spontaneous spatial mapping of learned sequence in chimpanzees: evidence for a SNARC-like effect. PLoS ONE 9:e90373. doi: 10.1371/journal.pone. 0090373

Bulf, H., de Hevia, M. D., and Macchi-Cassia, V. (2016). Small on the left, large on the right: numbers orient visual attention onto space in preverbal infants. Dev. Sci. 19, 394-401. doi: 10.1111/desc.12315

Daisley, J. N., Mascalzoni, E., Rosa Salva, O., Rugani, R., and Regolin, L. (2009). Lateralization of social cognition in the domestic chicken (Gallus gallus). Philos. Trans. R. Soc. Lond. B 364, 965-981. doi: 10.1098/rstb.2008.0229

Dehaene, S. (2011). The Number Sense: How the Mind Creates Mathematics, Revised and Updated Edition. New York, NY: Oxford University Press.

de Hevia, M. D., and Spelke, E. S. (2009). Spontaneous mapping of number and space in adults and young children. Cognition 110, 198-207. doi: 10.1016/j.cognition.2008.11.003

de Hevia, M. D., and Spelke, E. S. (2010). Number-Space Mapping in Human Infants. Psychol. Sci. 21, 653-660. doi: 10.1177/0956797610366091

Drucker, C. B., and Brannon, E. M. (2014). Rhesus monkeys (Macaca mulatta) map number onto space. Cognition 132, 57-67. doi: 10.1016/j.cognition.2014. 03.011

Lourenco, S. F., and Longo, M. R. (2010). General magnitude representation in human infants. Psychol. Sci. 21, 873-881. doi: 10.1177/09567976103 70158

Núñez, R., and Fias, W. (2015). Ancestral mental number lines: what is the evidence? Cogn. Sci. doi: 10.1111/cogs.12296. [Epub ahead of print].

Rogers, L. J., Vallortigara, G., and Andrew, R. J. (2013). Divided Brains: The Biology and Behavior of Brain Asymmetries. Cambridge, UK: Cambridge University Press.

Rugani, R., Kelly, M. D., Szelest, I., Regolin, L., and Vallortigara, G. (2010). It is only humans that count from left to right? Biol. Lett. 6, 290-292. doi: $10.1098 / \mathrm{rsbl} .2009 .0960$

Rugani, R., Regolin, L., and Vallortigara, G. (2007). Rudimental competence in 5-day-old domestic chicks: identification of ordinal position. J. Exp. five, initial bias to eight was to the right, whereas when chicks were trained on 20, the initial bias to eight was on the left.

In sum, the criticisms proposed by Núñez and Fias did not affect our results and their interpretation.

We believe that our study is a valid first step to better understand the phylogenetic and ontogenetic origin of spatialnumerical associations. Further studies are required to better understand the nature (e.g., logarithmic or linear) and the specific mapping rules that govern the MNL.

We are aware that we are just at the beginning of the investigation of number-space associations, but we strongly believe that future experimental studies will help to disentangle such a complex phenomenon.

\section{AUTHOR CONTRIBUTIONS}

RR and KP wrote the manuscript. LR and GV provided critical revision. All authors approved the final version of the manuscript for submission.
Psychol. Anim. Behav. Process. 33, 21-31. doi: 10.1037/0097-7403. 33.1.21

Rugani, R., Rosa Salva, O., and Regolin, L. (2014). Lateralized mechanisms for encoding of object. Behavioral evidence from an animal model: the domestic chick (Gallus gallus). Front. Psychol. 5:150. doi: 10.3389/fpsyg.2014.00150

Rugani, R., Vallortigara, G., Priftis, K., and Regolin, L. (2015a). Number-space mapping in the newborn chick resembles humans' mental number line. Science 347, 534-536. doi: 10.1126/science.aaa1379

Rugani, R., Vallortigara, G., Priftis, K., and Regolin, L. (2015b). Comments to" Number-space mapping in the newborn chick resembles humans' mental number line. Science 348, 1438. doi: 10.1126/science.aab0002

Rugani, R., Vallortigara, G., Vallini, B., and Regolin, L. (2011). Asymmetrical number-space mapping in the avian brain. Neurobiol. Learn. Mem. 95, 231-238. doi: 10.1016/j.nlm.2010.11.012

Umiltà, C., Priftis, K., and Zorzi, M. (2009). The spatial representation of numbers: evidence from neglect and pseudoneglect. Exp. Brain Res. 192, 561-569. doi: 10.1007/s00221-008-1623-2

Vallortigara, G., and Andrew, R. J. (1991). Lateralization in response to change in a model partner by chicks. Anim. Behav. 41, 187-194. doi: 10.1016/S00033472(05)80470-1

Vallortigara, G., Regolin, L., Bortolomiol, G., and Tommasi, L. (1996). Lateral asymmetries due to preferences in eye use during visual discrimination learning in chicks. Behav. Brain Res. 74, 135-143.

Conflict of Interest Statement: The authors declare that the research was conducted in the absence of any commercial or financial relationships that could be construed as a potential conflict of interest.

Copyright (c) 2016 Rugani, Vallortigara, Priftis and Regolin. This is an open-access article distributed under the terms of the Creative Commons Attribution License (CC $B Y)$. The use, distribution or reproduction in other forums is permitted, provided the original author(s) or licensor are credited and that the original publication in this journal is cited, in accordance with accepted academic practice. No use, distribution or reproduction is permitted which does not comply with these terms. 